Dublin, Ireland

\title{
The importance of embracing Lived Experience in education
}

\author{
Dr. Sal Corbin, Dr. Lukas Carey \\ Independent Scholar, Australia
}

\begin{abstract}
:
Education means different things to different people and happens in a multitude of ways. The importance of embracing the stories and lessons of individuals to assist the education journey of others is paramount. Increasing the authenticity and learning outcomes of students of all ages is a goal of all educators and something that teachers around the globe continue to source resources and method in which to do so. A proven, but often not embraced method of meeting these goals is the use of lived experience. This presentation will see two academics with lived experience from two diverse backgrounds and global locations share their own lived experience and how, if embraced, could increase the outcomes for students of all levels around the globe.
\end{abstract}

Keywords: Lived Experience, Education, Authenticity 